\title{
HMGB1 release by human liver L02 and HepG2 cells induced by lipopolysaccharide
}

\author{
ZE-BING HUANG ${ }^{1,2}$, XIA-HONG DAI ${ }^{3}$, MEI-FANG XIAO ${ }^{4}$, RONG-RONG ZHOU ${ }^{1,2}$, SHU-SHAN ZHAO $^{5}$, \\ BAO-XIN ZHANG ${ }^{6}$, PAN-PAN YI ${ }^{1,2}$, RUO-CHAN CHEN ${ }^{1,2}$, WEN-TING LI ${ }^{1,2}$, AI-MADHAGI YASER ${ }^{1,2}$, \\ YAN HUANG ${ }^{1,2}$ and XUE-GONG FAN ${ }^{1,2}$ \\ ${ }^{1}$ Department of Infectious Diseases, Xingya Hospital, Central South University; ${ }^{2}$ Key Laboratory of Viral Hepatitis, Hunan; \\ ${ }^{3}$ State Key Laboratory for Diagnosis and Treatment of Infectious Diseases, Zhejiang University, \\ Hangzhou, Zhejiang; ${ }^{4}$ Health Management Center; ${ }^{5}$ Eight-Year Program, Xiangya Hospital, \\ Central South University; ${ }^{6}$ Department of Infectious Diseases, Hunan Provincial Corps \\ Hospital of Chinese People's Armed Police Forces, Changsha, Hunan, P.R. China
}

Received July 18, 2012; Accepted April 26, 2013

DOI: $10.3892 / \mathrm{mmr} .2013 .1482$

\begin{abstract}
Liver cells release the high mobility group box-1 (HMGB1) protein when exposed to lipopolysaccharides (LPSs). However, the timing and levels of protein released remain unclear. The present study aimed to characterize the secretion of the late pro-inflammatory cytokine HMGB1 by liver L02 and HepG2 cells. The human mononuclear macrophage cell line U937 was used as a control. Various concentrations of LPS were added to human U937, L02 and HepG2 cells for different durations, and the cells were analyzed at different time-points following this addition. Reverse transcription polymerase chain reaction (RT-PCR) was used to measure cellular HMGB1 mRNA levels, western blotting was performed to detect HMGB1 in cellular supernatants and the translocation of HMGB1 from the nucleus to the cytosol was examined using immunofluorescence staining. L02 and HepG2 cells exhibited higher HMGB1 mRNA levels compared with the control U937 cells 20 and 24 h following continuous exposure to LPS. U937 cells exhibited higher HMGB1 mRNA levels compared with the corresponding L02 and HepG2 cells $16 \mathrm{~h}$ following LPS exposure. The phase of HMGB1 protein detected in the cellular supernatants of L02 and HepG2 cells (16 h) was later than that of U937 cells $(8 \mathrm{~h})$. For the three cell lines, HMGB1 levels demonstrated a time dependency; however, the protein level was the highest in U937 cells. In the three cell lines, translocation of HMGB1 from the nucleus to the cytosol occurred; however, the phases
\end{abstract}

Correspondence to: Professor Xue-Gong Fan and Dr Yan Huang, Department of Infectious Diseases, Xiangya Hospital, Central South University, 87 Xiangya Road, Changsha, Hunan 410008, P.R. China E-mail: xgfan@hotmail.com

E-mail: morninghy@yahoo.com.cn

Key words: high mobility group box-1 protein, lipopolysaccharide, U937 cell, L02 cell, HepG2 cell, release of HMGB1 translocation in L02 and HepG2 cells occurred later than in U937 cells. LPS-induced secretion of the late pro-inflammatory cytokine HMGB1 by liver cells is characterized by a late phase of release and smaller quantity, and the process of HMGB1 secretion appears to be associated with HMGB1 translocation.

\section{Introduction}

High mobility group box-1 (HMGB1) protein, discovered in the 1970 s, is a non-histone nucleoprotein, rich in eukaryotes. It has a highly conserved structure; the homology of the amino acid sequence between humans and rodents is $>99 \%$ (1). HMGB1 is widely distributed across different organs, including the lymph, heart, liver, kidney, lung and brain tissues of various species, and has evolved to be a substance necessary for life. Studies have demonstrated that $H M G B 1$ knock-out mice die several hours following their birth (2). The localization of HMGB1 in the nucleus is determined by two lysine-rich nuclear localization sequences (NLS). The N-terminus of HMGB1 contains two repeats of positively charged domains (A box and B box), and a negatively charged $\mathrm{C}$-terminus; these domains allow HMGB1 to bind to chromatin DNA, thus participating in DNA repair, replication, transcription and translation and the regulation of various cellular activities (3-5). The function of HMGB1 is related to its localization. HMGB1 in the nucleus participates in gene expression and regulation (6), whereas dynamically moving HMGB1 in the cytoplasm and nucleus is involved in regulating axon growth, the taxis of smooth muscle cells and the transfer of tumor cells $(7,8)$. Recent studies have demonstrated that when nuclear HMGB1 is released into the extracellular space, it serves as an inflammatory mediator that participates in numerous pathological and physiological processes, maintaining and augmenting inflammatory responses (9). Thus it has a key role in the complex cytokine secretion and regulatory network (10).

It is necessary for HMGB1 to be released into the extracellular space in order to exert an inflammatory effect. In the 
extracellular space, HMGB1 is a key 'late' pro-inflammatory cytokine. In 1999, Wang et al reported the important role of HMGB1 in sepsis (9). In recent years, there have been an increasing number of studies demonstrating that HMGB1 is involved in various diseases. As a pro-inflammatory cytokine, the pathogenic action of HMGB1 has two prominent characteristics. Firstly, the time at which HMGB1 takes effect is relatively late. Unlike early pro-inflammatory cytokines, such as the commonly seen tumor necrosis factor- $\alpha$ (TNF- $\alpha$ ), HMGB1 is not released into the extracellular space to exert its inflammatory effect until at least $20 \mathrm{~h}$ following stimulation $(2,9)$. However, this is not the case in ischemia-reperfusion injuries (11); it has been demostrated that in ischemia-reperfusion models, HMGB1 release occurs within $4 \mathrm{~h}$ of stimulation, although the mechanism of this process remains unclear. Secondly, HMGB1 is capable of sustaining and augmenting the inflammatory response. It serves as an inflammatory cytokine that participates in signal transduction and also interacts with multiple pro-inflammatory cytokines to mutually induce expression (12); it may also lead to the nuclear translocation of the inflammatory signal molecule nuclear factor (NF)-кB $(13,14)$. HMGB1 contributes to a complex cytokine secretion and regulatory network that initiates, sustains and augments the inflammatory response. HMGB1 is a key component of the inflammatory cytokine network (10), not only due to the cascade effect of its own secretions, but also due to its role in regulating the secretions of other inflammatory factors. HMGB1 has two methods of release; active 'secretion' (15) by activated immune cells and passive 'leaking' from apoptotic cells (16). HMGB1 secretion by activated immune cells has been widely studied, however there have been relatively few studies with regard to HMGB1 secretion by non-apoptotic cell entities. Previous studies by our group have found that under TNF- $\alpha$ and LPS stimulation, a large amount of HMGB1 may be detected in the supernatants of liver cell cultures $(17,18)$, consistent with the results of Tsung et al (19). This was a novel finding for the physiological function of the liver. However, the process of HMGB1 release by liver cells remains unclear. In this study, HMGB1 release by the human mononuclear macrophage cell line U937 was used as a reference, and the release of the late pro-inflammatory cytokine HMGB1 by apoptotic liver cells was investigated.

\section{Materials and methods}

Cell lines. Human mononuclear macrophage cell line U937 and human liver cell lines L02 and HepG2 were purchased from the cell bank of Shanghai Institute of Biochemistry and Cell Biology, Chinese Academy of Science (Shanghai, China).

Study design. Cell lines L02, HepG2 and U937 were regularly cultured. The number of cells was adjusted to $2.0 \times 10^{6}$, and the cells were transferred to opti-MEM1 low-serum medium (Gibco, Carlsbad, CA, USA) for $4 \mathrm{~h}$. Subsequently, LPS at a specific final concentration was added and cellular supernatants were collected at various time-points $(0,4$, $8,12,16,20$ and $24 \mathrm{~h})$. Western blotting was performed to measure the HMGB1 protein level and a methyl thiazolyl tetrazolium (MTT) assay was performed in order to detect the survival rate of the cells. HMGB1 mRNA levels were measured by reverse transcription polymerase chain reaction (RT-PCR) , apoptosis was detected using a fluorescent TUNEL assay (Roche, USA) and HMGB1 translocation was examined by immunofluorescence. Three independent measurements were performed and results were averaged.

MTT assay. L02, HepG2 and U937 cells were cultured in 96-well plates and treated with varying concentrations of LPS for different durations. MTT ( $20 \mu 1$; Sigma, St. Louis, MO, USA) was added to each well and cultured in an incubator at $37^{\circ} \mathrm{C}$ for $4 \mathrm{~h}$. The supernatant was then discarded and $150 \mu \mathrm{l}$ DMSO was added to each well and agitated for $10 \mathrm{~min}$. An automated ELISA analyzer (Chondrex, USA) was used for chromatometry. For the corresponding control group, normal saline (NS) of the same volume as LPS was added; DMSO and a low-serum medium were used for the baseline group. The cell survival rate was calculated according to the following formula: survival rate $=(\mathrm{OD}$ experimental group - OD baseline group)/(OD control group - OD baseline group).

Measurement of lactic dehydrogenase $(L D H)$ content. Cellular supernatants of the HepG2, L02 and U937 cells were collected at various time-points $(0,4,8,12,16,20$ and $24 \mathrm{~h})$ and centrifuged to remove cell fragments. An Amicon Ultra-4 ml $10 \mathrm{KD}$ ultrafiltration centrifugal tube (Millipore Inc., Billerica, MA, USA) was used to concentrate the solution 20-50 times. LDH contents of the groups were subjected to routine detection at the biochemistry laboratory of Xiangya Hospital, Central South University (Changsha, China).

Detection of apoptosis by fluorescent TUNEL assay. After each of the groups were treated, the cells were fixed with $4 \%$ pre-cooled paraformaldehyde, placed on a horizontal shaker at $25^{\circ} \mathrm{C}$ and subjected to gentle agitation for $60 \mathrm{~min}$. Next, $0.1 \mathrm{ml}$ permeating liquid was added and allowed to settle at $4^{\circ} \mathrm{C}$ for $10 \mathrm{~min} ; 50 \mu \mathrm{l}$ TUNEL reaction mixture (Boehringer Mannheim, Germany) was added to the wells of each experimental group and reacted in the dark for 60 min at $37^{\circ} \mathrm{C}$. Freshly prepared DAPI working solution (1-2 drops of $2 \mathrm{mg} / \mathrm{l}$ ) was added to stain the nuclei and cells were observed under a fluorescent microscope. Negative and positive control wells were also prepared. In the negative control well, the reaction mixture was replaced by Vial 2 solution (Roche) and the well was placed in the dark for $1 \mathrm{~h}$. In the positive control well, following permeation, $3 \mathrm{U} / \mathrm{ml}$ DNase I (Sigma) was added and allowed to react for $10 \mathrm{~min}$ at $25^{\circ} \mathrm{C}$. Subsequently, the reaction mixture was added for the TUNEL reaction.

Detection of HMGBI mRNA level by RT-PCR. After treating each group, total RNA extraction and RT were performed according to the manufacturer's instructions (Qiagen RNeasy Mini Extraction kit, Qiagen, Inc., Hilden, Germany). The PCR primer was designed using Primer premier 5.0 software based on human HMGB1 and $\beta$-actin cDNA sequences in the Genbank. The primers were synthesized by Shanghai Sangon Biotech Co., Ltd. (Shanghai, China) and their sequences were as follows: HMGB1, GAG CAT AAG AAG AAG CAC CCA GAT GGG CGA TAC TCA GAG CAG AAG (target fragment, 257 bp); and $\beta$-actin, GAC AGG ATG CAG AAG GAG ATT 
ACT TGA TCC ACA TCT GCT GGA AGG T (target fragment, $142 \mathrm{bp}$ ). The PCR reaction conditions for HMGB1 were as follows: $94^{\circ} \mathrm{C}$ for $4 \mathrm{~min}, 94^{\circ} \mathrm{C}$ for $30 \mathrm{sec}, 58^{\circ} \mathrm{C}$ for $30 \mathrm{sec}$, $72^{\circ} \mathrm{C}$ for $30 \mathrm{sec}$, and 32 cycles of $72^{\circ} \mathrm{C}$ for $7 \mathrm{~min}$. The PCR reaction conditions for $\beta$-actin were as follows: $94^{\circ} \mathrm{C}$ for $5 \mathrm{~min}$, $94^{\circ} \mathrm{C}$ for $30 \mathrm{sec}, 55^{\circ} \mathrm{C}$ for $30 \mathrm{sec}, 72^{\circ} \mathrm{C}$ for $30 \mathrm{sec}$ and 30 cycles of $72^{\circ} \mathrm{C}$ for $7 \mathrm{~min}$. Subsequently, PCR products $(5 \mu \mathrm{l})$ were subjected to $2 \%$ agarose gel electrophoresis and images were captured under UV light. A bandscan imaging analysis system (Eagle Eye II, Stralagene, USA) was used to scan the bands and the photodensity of each band was acquired. The relative band density of HMGB1 was calculated.

Measurement of HMGB1 protein by western blotting. The cell culture supernatants from each group were collected and the cell fragments were filtered out. An Amicon Ultra-4ml $10 \mathrm{KD}$ ultrafiltration centrifugal tube (Millipore Inc.) was used to concentrate the solution and the Coomassie brilliant blue method (Sigma) was used to measure the protein content. To a $40 \mu \mathrm{l}$ sample, a loading buffer of the same volume was added and mixed, and the mixture was subjected to denaturation by boiling. Separating gel (10\% SDS-PAGE) and 5\% spacer gel were prepared, and the samples were loaded for electrophoresis in an electrophoresis buffer. The gels were electrotransferred to polyvinylidine difluoride (PVDF) membranes. After blocking with a buffer containing 5\% skim milk powder for $30 \mathrm{~min}$, rabbit anti-human polyclonal antibody (Abcam, USA; 1:1,000 dilution)was added for an overnight reaction at $4^{\circ} \mathrm{C}$. Following washing with Tris-buffered saline with Tween-20 (TBST), the PVDF membranes were incubated with a secondary antibody (Merck, Germany; 1:500 dilution) for $1 \mathrm{~h}$ at $37^{\circ} \mathrm{C}$. Following a further TBST wash, exposure, development, fixation and positive image production were performed using the ECL Western Blotting Detection kit (Amersham Pharmacia Biotech, Amersham, UK), according to the manufacturer's instructions . The film was scanned and photodensity was analyzed using Quantity One software (Bio-Rad, Hercules, CA, USA). The relative protein content of different samples was calculated based on the known concentration of recombinant human HMGB1.

HMGB1 translocation detection. Following each treatment period, the cell supernatant from each group was discarded. After three washes with PBS, cells were fixed with $4 \%$ paraformaldehyde for $15 \mathrm{~min}$. The cells were dried at room temperature, subsequently treated with $0.1 \%$ Triton $\mathrm{x}-100$ at $4^{\circ} \mathrm{C}$ for $10 \mathrm{~min}$ and then blocking at room temperature was performed for 30 min using a blocking buffer. The cells were spun dry and rabbit anti-human polyclonal antibody (1:1000 dilution) was added for an overnight incubation at $4^{\circ} \mathrm{C}$. Subsequently, following three washes with PBS, a fluorescein isothiocyanate (FITC)-labeled fluorescent secondary antibody (1:750 dilution) was added for incubation at $37^{\circ} \mathrm{C}$ for 120 min. Following a further three washes with PBS, DAPI (final concentration, $5 \mu \mathrm{mol} / \mathrm{l}$ ) was used for double staining at room temperature for $10 \mathrm{~min}$, and glycerol jelly was used to mount the slides. The slides were examined under a fluorescent microscope, and Image-Pro Plus software (Media Cybernetics, Rockville, MD, USA) was used for semi-quantitative analysis of the relative fluorescence intensity in the nuclei and cytoplasm.

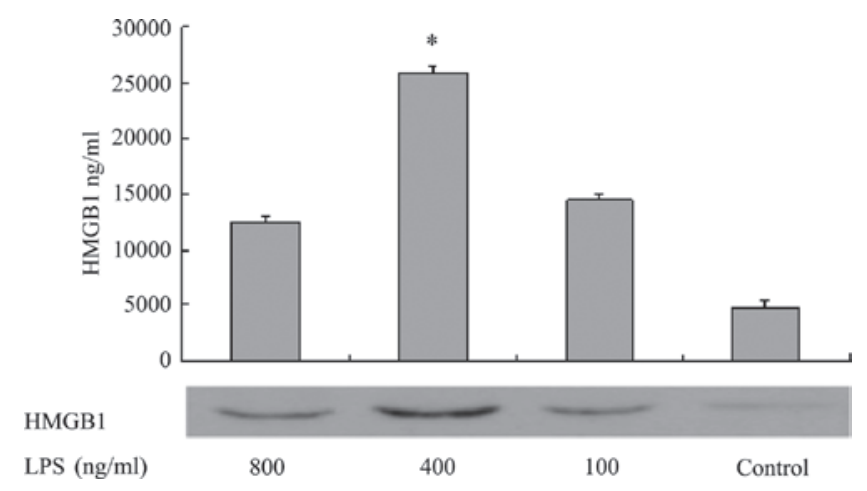

Figure 1. Relative high mobility group box-1 (HMGB1) protein content in the supernatant of L02 cells using western blotting $20 \mathrm{~h}$ after the addition of various concentrations of lipopolysaccharide (LPS). "HMGB1 content at $400 \mathrm{ng} / \mathrm{ml}$ LPS was significantly higher than that at the other three LPS concentrations $(\mathrm{P}<0.05, \mathrm{n}=3)$.

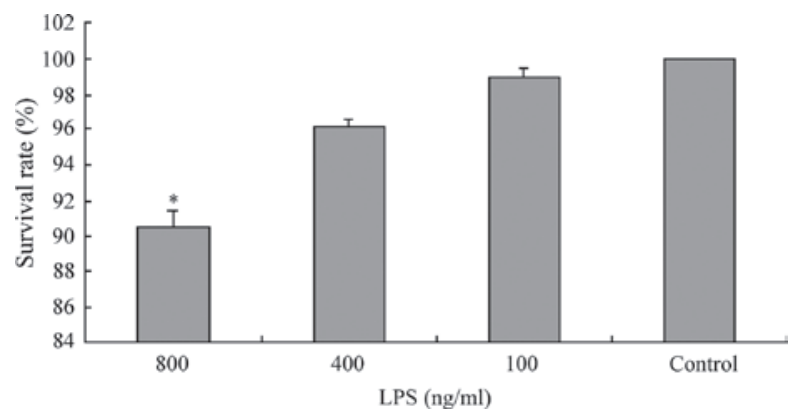

Figure 2. Survival rate $(\%$, mean \pm SD) of L02 cells $20 \mathrm{~h}$ after the addition of various concentrations of lipopolysaccharide (LPS). "When the concentration of LPS reached $800 \mathrm{ng} / \mathrm{ml}$, the survival rate decreased significantly $(\mathrm{P}<0.05)$.

Statistical analysis. The SPSS 13.0 software package was used to analyze and process the data. A t-test was performed for comparison between the groups and analysis of variance (ANOVA) was performed for comparison within a group. $\mathrm{P}<0.05$ was considered to indicate a statistically significant difference.

\section{Results}

Effects of stimulation with various concentrations of LPS. Western blotting was performed to measure HMGB1 levels in the supernatants of L02 cells $20 \mathrm{~h}$ after the addition of various concentrations of LPS. The results demonstrated that when the LPS concentration was in the range of $0-400 \mathrm{ng} / \mathrm{ml}$, the concentration of HMGB1 in the cell culture supernatant increased as the LPS concentration increased. However, when the LPS concentration was $>400 \mathrm{ng} / \mathrm{ml}$, the concentration of HMGB1 in the supernatant no longer increased. At the final LPS concentration of $800 \mathrm{ng} / \mathrm{ml}$, the HMGBI content was significantly lower than that when the LPS concentration was $400 \mathrm{ng} / \mathrm{ml}(\mathrm{P}<0.05$, Fig. 1). The MTT assay measured the survival rates of L02 cells following $20 \mathrm{~h}$ of continuous exposure to LPS at various concentrations $(100,400,800 \mathrm{ng} / \mathrm{ml})$. The results demonstrated that when the LPS concentration was in the range $0-400 \mathrm{ng} / \mathrm{ml}$, the survival rate of L02 cells was $>95 \%(99.99 \pm 0.01,98.97 \pm 0.52$ and $96.18 \pm 0.34 \%$ for the control, LPS $100 \mathrm{ng} / \mathrm{ml}$ and $400 \mathrm{ng} / \mathrm{ml}$ groups, respectively). 
Table I. Survival rates of HepG2, L02 and U937 cells at various time-points following the addition of LPS, measured by an MTT assay (mean $\pm \mathrm{SD}, \mathrm{n}=3$ ).

\begin{tabular}{lccccccc}
\hline & \multicolumn{8}{c}{ Survival rate (\%) } \\
\cline { 2 - 7 } Group & $4 \mathrm{~h}$ & $8 \mathrm{~h}$ & $12 \mathrm{~h}$ & $16 \mathrm{~h}$ & $20 \mathrm{~h}$ & $24 \mathrm{~h}$ & $48 \mathrm{~h}$ \\
\hline HepG2 & $99.30 \pm 0.18$ & $98.63 \pm 0.22$ & $96.98 \pm 0.79$ & $95.47 \pm 2.14$ & $94.24 \pm 0.99$ & $91.01 \pm 1.17$ & $83.54 \pm 1.26^{\mathrm{a}}$ \\
LO2 & $99.52 \pm 0.29$ & $98.37 \pm 0.89$ & $95.94 \pm 4.13$ & $95.46 \pm 1.73$ & $92.87 \pm 1.79$ & $90.76 \pm 0.91$ & $82.77 \pm 1.06^{\mathrm{a}}$ \\
U937 & $99.41 \pm 0.35$ & $97.73 \pm 0.86$ & $96.65 \pm 0.31$ & $94.42 \pm 1.86$ & $91.75 \pm 3.11$ & $91.21 \pm 2.033$ & $81.88 \pm 0.96^{\mathrm{a}}$ \\
\hline
\end{tabular}

${ }^{a}$ At $48 \mathrm{~h}$ following the addition of LPS, the survival rates of cells from all groups significantly decreased $(\mathrm{P}<0.05)$. LPS, lipopolysaccharide; MTT, methyl thiazolyl tetrazolium.

Table II. LDH content in the supernatant of cells from different groups at various time-points following the addition of LPS $($ mean $\pm \mathrm{SD}, \mathrm{n}=3)$.

LDH content (U/l)

\begin{tabular}{lcccccc}
\cline { 2 - 7 } Group & $4 \mathrm{~h}$ & $8 \mathrm{~h}$ & $12 \mathrm{~h}$ & $16 \mathrm{~h}$ & $20 \mathrm{~h}$ & $24 \mathrm{~h}$ \\
\hline HepG2 + NS & $0.0257 \pm 0.0021$ & $0.1428 \pm 0.0024$ & $0.1868 \pm 0.0068$ & $0.2607 \pm 0.0175$ & $0.4234 \pm 0.0563$ & $1.1049 \pm 0.0831$ \\
HepG2 + LPS & $0.0274 \pm 0.0018$ & $0.1382 \pm 0.0046$ & $0.1948 \pm 0.0057$ & $0.2768 \pm 0.0368$ & $0.4580 \pm 0.0242$ & $1.1830 \pm 0.0732$ \\
L02 + NS & $0.0247 \pm 0.0007$ & $0.1091 \pm 0.0094$ & $0.1162 \pm 0.0054$ & $0.1191 \pm 0.0049$ & $0.4173 \pm 0.0200$ & $1.3330 \pm 0.2947$ \\
L02 + LPS & $0.0252 \pm 0.0049$ & $0.1181 \pm 0.0118$ & $0.1212 \pm 0.0022$ & $0.1374 \pm 0.0050$ & $0.4221 \pm 0.0342$ & $1.2616 \pm 0.1579$ \\
U937 + NS & $0.0265 \pm 0.0022$ & $0.1369 \pm 0.0021$ & $0.1350 \pm 0.0092$ & $0.1354 \pm 0.0142$ & $0.4365 \pm 0.0096$ & $1.7306 \pm 0.0373$ \\
U937 + LPS & $0.0294 \pm 0.0024$ & $0.1398 \pm 0.0086$ & $0.1454 \pm 0.0232$ & $0.1477 \pm 0.0199$ & $0.4487 \pm 0.0288$ & $1.5532 \pm 0.2679$
\end{tabular}

There was no significant difference between any of the LPS-treated and corresponding control groups (P>0.05). LDH, lactic dehydrogenase; LPS, lipopolysaccharide; NS, normal saline.

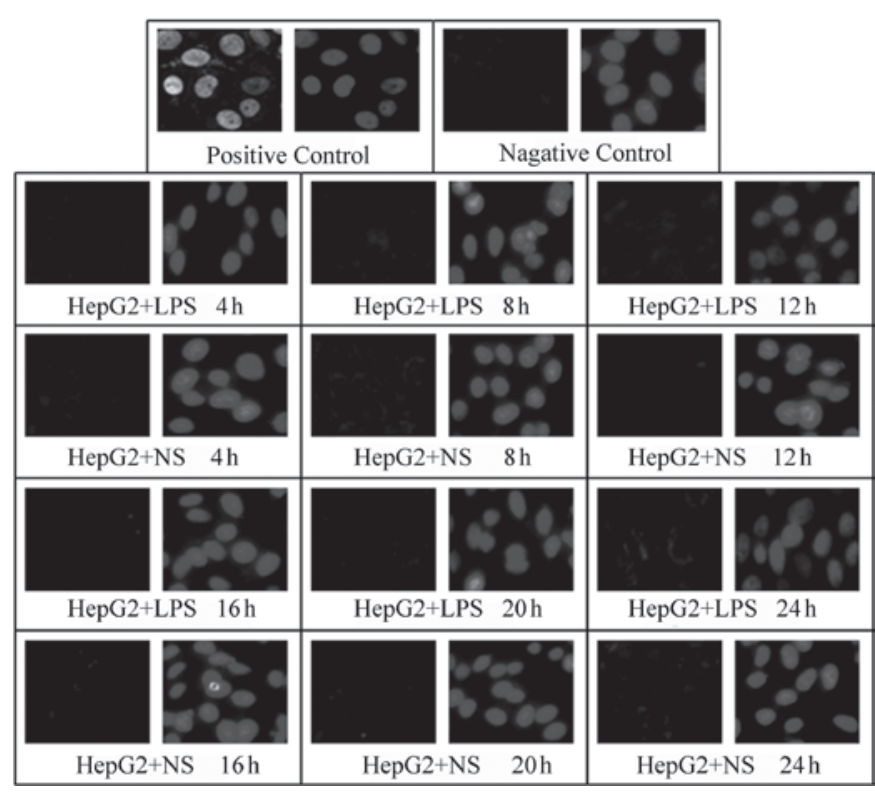

Figure 3. Effect of lipopolysaccharide (LPS) stimuli on HepG2 apoptosis, as determined by a TUNEL assay. At 0-20 h, neither cells from LPS-treated groups nor those from the corresponding control groups demonstrated notable fluorescence; at $24 \mathrm{~h}$, a small amount of non-specific fluorescence was observed. Semi-quantitative analysis demonstrated that there was no significant difference between the rates of apoptosis in the experimental and control groups $(\mathrm{P}>0.05)$.

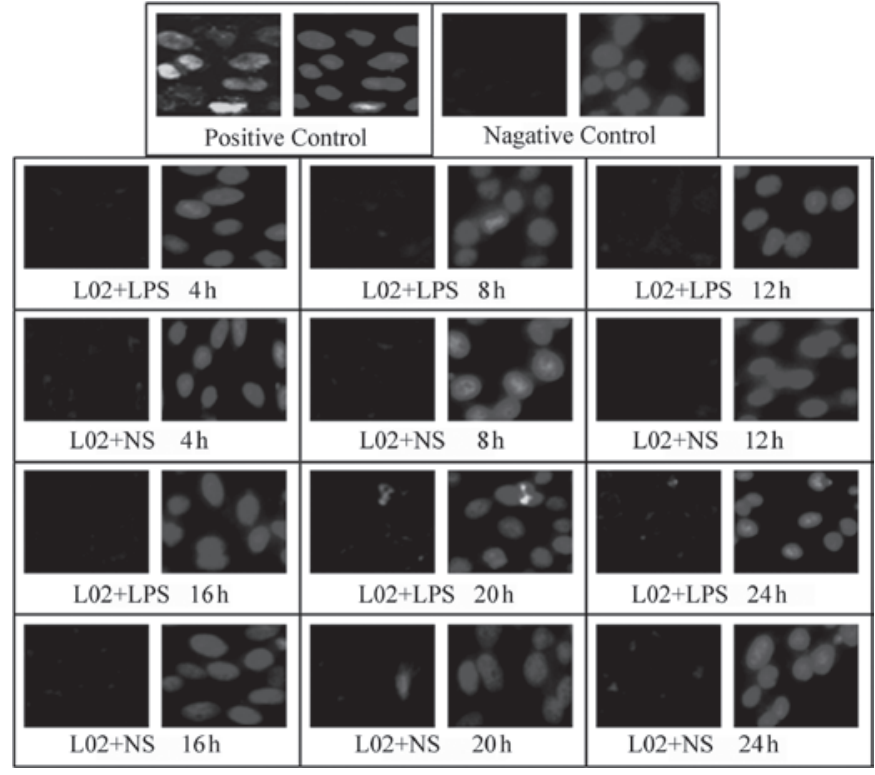

Figure 4. Effect of lipopolysaccharide (LPS) stimuli on L02 apoptosis, as determined by a TUNEL assay. At $0-16 \mathrm{~h}$, neither cells from LPS-treated groups nor those from the corresponding control groups demonstrated notable fluorescence; at 20 and $24 \mathrm{~h}$ a small amount of non-specific fluorescence was observed. Semi-quantitative analysis demonstrated that there was no significant difference between the rates of apoptosis rate in the experimental and control groups $(\mathrm{P}>0.05)$. 


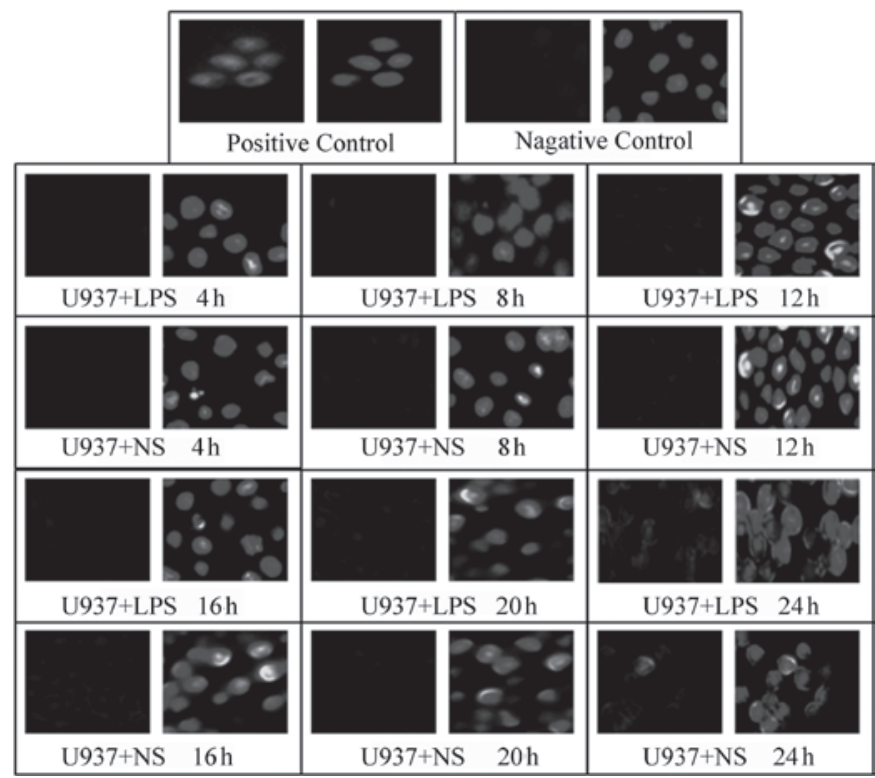

Figure 5. Effect of lipopolysaccharide (LPS) stimuli on U937 apoptosis, as determined by a TUNEL assay. At $0-20 \mathrm{~h}$, neither cells from LPS-treated groups nor those from the corresponding control groups exhibited notable fluorescence; at $24 \mathrm{~h}$ a small amount of non-specific fluorescence was observed. Semi-quantitative analysis demonstrated that there was no significant difference between the apoptosis rates in any of the experimental and control groups $(\mathrm{P}>0.05)$.

However, when the concentration of LPS was increased to $800 \mathrm{ng} / \mathrm{ml}$, the survival rate of the L02 cells significantly decreased to $90.59 \pm 0.76 \%$ (Fig. 2).

Survival rates of Hep G2, LO2 and U937 cells at various timepoints following the addition of LPS. As shown in Table I, at 0-24 $\mathrm{h}$ following the addition of LPS, the survival rates of HepG2, L02 and U937 cells were all $>90 \%$. However, at $48 \mathrm{~h}$, the survival rates significantly decreased $(\mathrm{P}<0.05)$, and the level of HMGBl released passively by apoptotic cells also increased. Therefore, we selected 0-24 h following treatment with LPS to be the range for the measurement of damage-related factor $\mathrm{LDH}$, apoptosis detection, measurement of HMGB1 mRNA levels using RT-PCR and the measurement of HMGB1 protein levels using western blotting.

LDH contents in the supernatants of HepG2, LO2 and U937 cells at various time-points following the addition of LPS. The LDH content in the supernatants of HepG2, L02 and U937 cells were measured at different time-points $(0-24 \mathrm{~h})$ following the addition of $400 \mathrm{ng} / \mathrm{ml}$ LPS. The results demonstrated that the LDH content in the cell supernatants of different groups gradually increased with time; for each group, the LDH content in the supernatant at $24 \mathrm{~h}$ was significantly higher than that at $0-20 \mathrm{~h}(\mathrm{P}<0.05)$. However, at each time-point, there was no significant difference in the LDH content in the cell supernatants between the LPS-treated and corresponding control groups $(\mathrm{P}>0.05$; Table II).

Effect of LPS stimulation on the apoptosis of HepG2, LO2 and U937 cells. A TUNEL assay was used to detect the effect of LPS (400 ng/ml) stimulation on the apoptosis of HepG2, L02

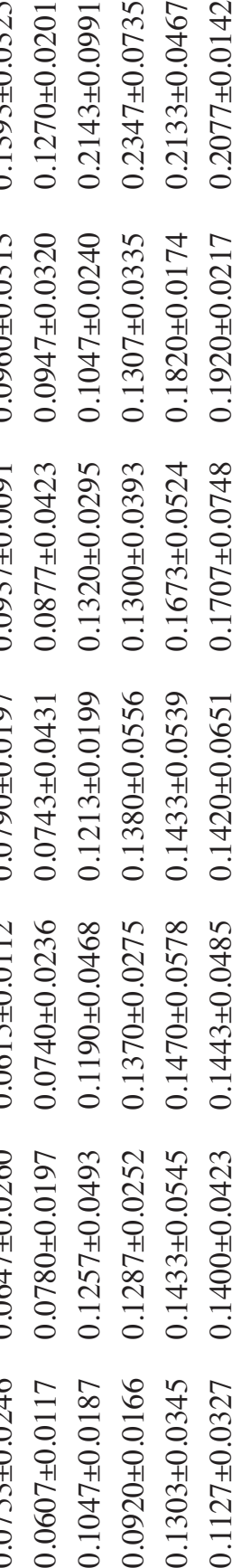


Table IV. Relative fluorescence intensity of cells from different groups at various time-points following the addition of LPS (mean $\pm \mathrm{SD}, \mathrm{n}=3$ ).

Fluorescence intenstity (\%)

\begin{tabular}{|c|c|c|c|c|c|c|c|}
\hline Group & $0 \mathrm{~h}$ & $4 \mathrm{~h}$ & $8 \mathrm{~h}$ & $12 \mathrm{~h}$ & $16 \mathrm{~h}$ & $20 \mathrm{~h}$ & $24 \mathrm{~h}$ \\
\hline \multicolumn{8}{|c|}{ L02 + LPS } \\
\hline $\mathrm{N}$ & $64.58 \pm 3.11 .$. & $63.95 \pm 4.66$. & $64.16 \pm 1.52 .$. & $49.75 \pm 3.03$ & $39.24 \pm 3.20$ & $28.48 \pm 5.15$ & $22.36 \pm 3.38$ \\
\hline $\mathrm{C}$ & $5.16 \pm 1.43$ & $4.65 \pm 0.59$ & $3.90 \pm 1.28$ & $19.04 \pm 1.42^{\mathrm{a}}$ & $28.83 \pm 3.61^{\mathrm{a}}$ & $42.04 \pm 9.54^{\mathrm{a}}$ & $34.07 \pm 5.12^{\mathrm{a}}$ \\
\hline \multicolumn{8}{|c|}{$\mathrm{L} 02+\mathrm{NS}$} \\
\hline $\mathrm{N}$ & $63.09 \pm 3.83 .$. & $62.21 \pm 5.44 .$. & $64.05 \pm 4.03 .$. & $60.93 \pm 8.93$ & $61.37 \pm 7.68$ & $56.85 \pm 6.98$ & $49.85 \pm 6.47$ \\
\hline $\mathrm{C}$ & $4.52 \pm 0.56$ & $4.37 \pm 1.54$ & $4.32 \pm 0.99$ & $5.68 \pm 1.17$ & $7.05 \pm 1.47$ & $9.74 \pm 2.87$ & $14.40 \pm 4.07$ \\
\hline \multicolumn{8}{|c|}{ HepG2 + LPS } \\
\hline $\mathrm{N}$ & $69.13 \pm 1.69 .$. & $68.38 \pm 3.21 .$. & $68.20 \pm 2.93 .$. & $59.48 \pm 3.81$ & $44.32 \pm 4.46$ & $34.21 \pm 3.40$ & $26.70 \pm 7.32$ \\
\hline $\mathrm{C}$ & $3.65 \pm 0.67$ & $3.86 \pm 1.39$ & $4.55 \pm 1.81$ & $14.74 \pm 1.34^{\mathrm{a}}$ & $27.06 \pm 3.59^{\mathrm{a}}$ & $45.51 \pm 5.16^{\mathrm{a}}$ & $33.67 \pm 3.86^{\mathrm{a}}$ \\
\hline \multicolumn{8}{|c|}{$\mathrm{HepG} 2+\mathrm{NS}$} \\
\hline $\mathrm{N}$ & $69.87 \pm 4.72 .$. & $71.17 \pm 4.28$. & $71.05 \pm 1.81 .$. & $70.77 \pm 8.18$ & $67.52 \pm 7.74$ & $63.77 \pm 5.07$ & $51.95 \pm 5.93$ \\
\hline $\mathrm{C}$ & $3.14 \pm 1.50$ & $3.62 \pm 1.67$ & $4.77 \pm 2.42$ & $4.73 \pm 1.66$ & $5.89 \pm 2.54$ & $7.72 \pm 2.70$ & $16.29 \pm 3.01$ \\
\hline \multicolumn{8}{|c|}{ U937 + LPS } \\
\hline $\mathrm{N}$ & $52.47 \pm 3.61 .$. & $50.30 \pm 4.36$. & $42.50 \pm 1.80 .$. & $35.41 \pm 2.47$ & $30.07 \pm 2.55$ & $25.65 \pm 3.51$ & $23.96 \pm 4.64$ \\
\hline $\mathrm{C}$ & $1.90 \pm 0.65$ & $3.94 \pm 1.15$ & $10.91 \pm 1.17^{\mathrm{b}}$. & $19.35 \pm 1.50^{\mathrm{b}}$ & $25.44 \pm 1.06^{\mathrm{b}}$ & $34.31 \pm 2.97^{\mathrm{b}}$ & $26.67 \pm 3.87^{b}$ \\
\hline \multicolumn{8}{|c|}{ U937 + NS } \\
\hline $\mathrm{N}$ & $53.45 \pm 4.31 .$. & $52.77 \pm 6.76 .$. & $52.45 \pm 5.17 .$. & $53.51 \pm 3.10$ & $51.40 \pm 6.34$ & $48.38 \pm 7.22$ & $42.26 \pm 7.17$ \\
\hline $\mathrm{C}$ & $1.95 \pm 1.69$ & $1.87 \pm 0.99$ & $2.30 \pm 1.21$ & $2.16 \pm 0.57$ & $2.8 \pm 0.67$ & $6.98 \pm 1.51$ & $12.77 \pm 1.24$ \\
\hline
\end{tabular}

Semi-quantitative fluorescence analysis showed that at 12-24 h, the fluorescence intensities in the cytoplasm of HepG2 and L02 cells from the LPS-treated group were significantly higher than those in the corresponding controls $\left({ }^{a} \mathrm{P}<0.05\right)$; whereas in U937 cells, starting at $8 \mathrm{~h}$, the fluorescence intensity in the cytoplasm of cells from the LPS-treated group was significantly higher than in the corresponding controls $\left({ }^{\mathrm{b}} \mathrm{P}<0.05\right)$. LPS, lipopolysaccharide; NS, normal saline; N, nuclei; C, cytoplasm.

and U937 cells at various time-points following the addition of $\operatorname{LPS}(4,8,12,16,20$ and $24 \mathrm{~h})$; NS of the same volume was added to the corresponding control groups. In the positive control, green fluorescence was observed in complete or broken nuclei and blue fluorescence in the same field of view marked cell nuclei double-stained by DAPI. As shown in Figs. 3-5, it was observed that there was little non-specific fluorescence in the HepG2, L02 and U937 cells at various time-points (high magnification). The relative fluorescence intensities of various cells are shown in Table III; there were no significant differences between the different time-points. Furthermore, at the same time-points, there were no significant differences between the LPS-treated and corresponding control groups $(\mathrm{P}>0.05)$.

Effect of LPS stimulation on HMGB1 translocation in Hep G2, LO2 and U937 cells. An immunofluorescence assay was used to examine HMGB1 translocation in HepG2, L02 and U937 cells at different time-points following the addition of LPS (400 ng/ml; 0, 4, 8, 12, 16, 20 and $24 \mathrm{~h}$ ). Under normal conditions, HMGB1 in HepG2, L02 and U937 cells was concentrated in the nuclei. Following treatment with $400 \mathrm{ng} / \mathrm{ml}$ LPS, green fluorescence from specifically labeled HMGBl was observed at $12 \mathrm{~h}$ in the cytosol of HepG2 and L02 cells; the fluorescence in the cytoplasm increased, whereas that in the nuclei decreased with time, suggestive of the translocation of HMGBl from the nuclei to the cytoplasm. In the corresponding control group, a small amount of fluorescence was observed in the cytoplasm, but the majority remained in the nuclei (Figs. 6 and 7). Relative fluorescence intensities of the groups were analyzed further by Image-Pro Plus software and are shown in Table IV. The results revealed that compared with 16 and $20 \mathrm{~h}$ following the addition of LPS, the total fluorescence at $24 \mathrm{~h}$ in the cytoplasm and nuclei of HepG2 and L02 cells was significantly reduced $(\mathrm{P}<0.05)$. Furthermore, at 0,4 and $8 \mathrm{~h}$ following the addition of LPS, there was no difference in fluorescence intensity in the cytoplasm or nuclei of cells between the LPS-treated HepG2 or L02 group and the corresponding control group ( $\mathrm{P}>0.05)$. However, at 12-24 h, the fluorescence intensities in the cytoplasm of cells from the LPS-treated HepG2 and L02 groups were significantly higher than those of the corresponding control groups $(\mathrm{P}<0.05)$.

The translocation of HMGBl from the nuclei to the cytoplasm in U937 cells occurred earlier than in HepG2 and L02 cells; at $\sim 4 \mathrm{~h}$, green fluorescence was observed in the cytoplasm and at $8 \mathrm{~h}$, a substantial degree of green fluorescence was observed in the cytoplasm of U937 cells. At 20 and $24 \mathrm{~h}$, the green fluorescence in the cytoplasm was markedly decreased. For cells of the control group (NS-treated), the green fluores- 


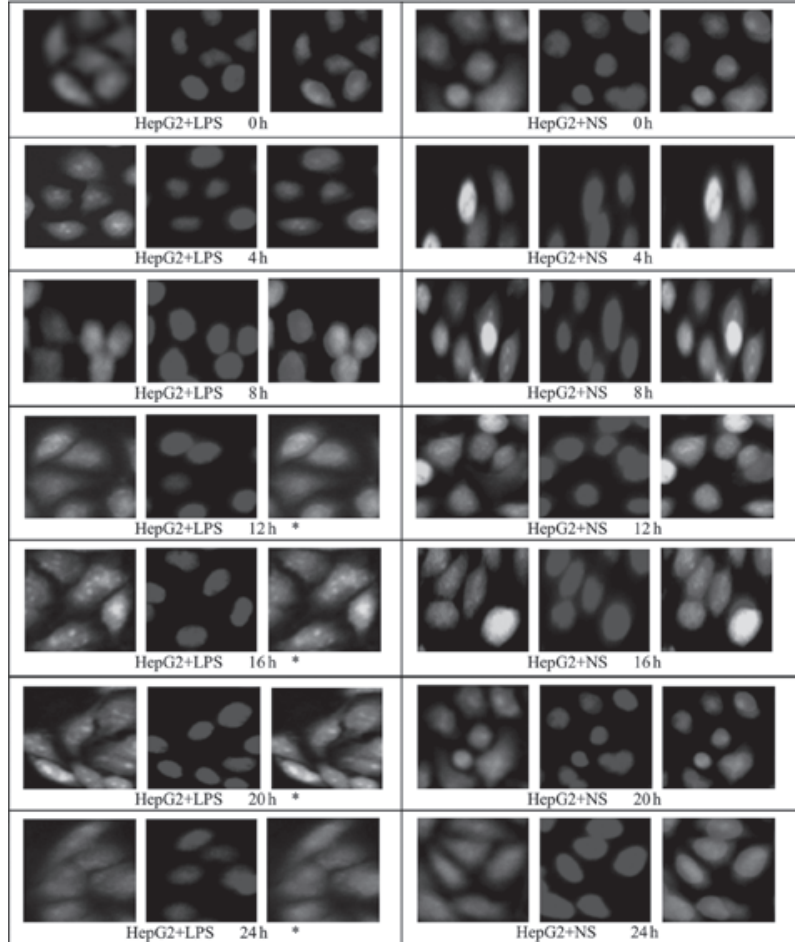

Figure 6. High mobility group box-1 (HMGB1) translocation in HepG2 cells, as detected by an immunofluorescence assay at various time-points following the addition of lipopolysaccharide (LPS; $400 \mathrm{ng} / \mathrm{ml}$; magnification, x200). A 12-24 h, substantial fluorescence was detected in the cytosol of LPS-treated HepG2 cells; however, in the corresponding control group, fluorescence was mainly detected in the nuclei. Semi-quantitative analysis revealed that this difference was significant $\left({ }^{*} \mathrm{P}<0.05\right)$.

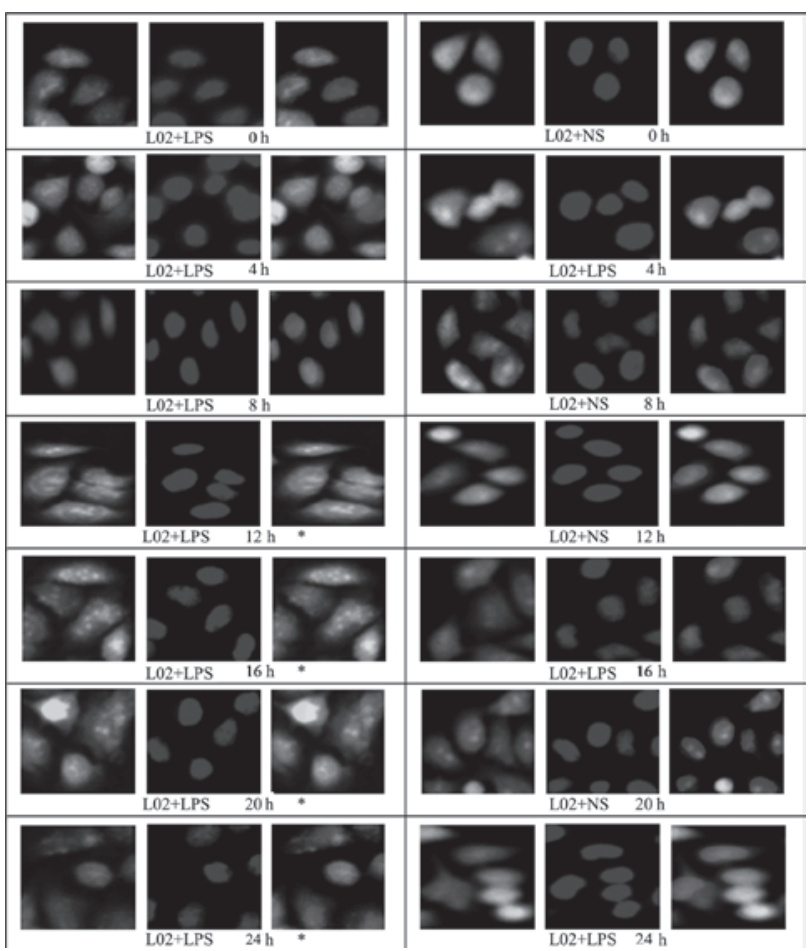

Figure 7. High mobility group box-1 (HMGB1) translocation in L02 cells, as detected by an immunofluorescence assay at various time-points following the addition of lipopolysaccharide (LPS; $400 \mathrm{ng} / \mathrm{ml}$; magnification, x200). At 12-24 h, substantial fluorescence was detected in the cytosol of LPS-treated L02 cells, whereas in the corresponding control group, fluorescence was mainly detected in the nuclei. Semi-quantitative analysis revealed that this difference was significant $(" \mathrm{P}<0.05)$.

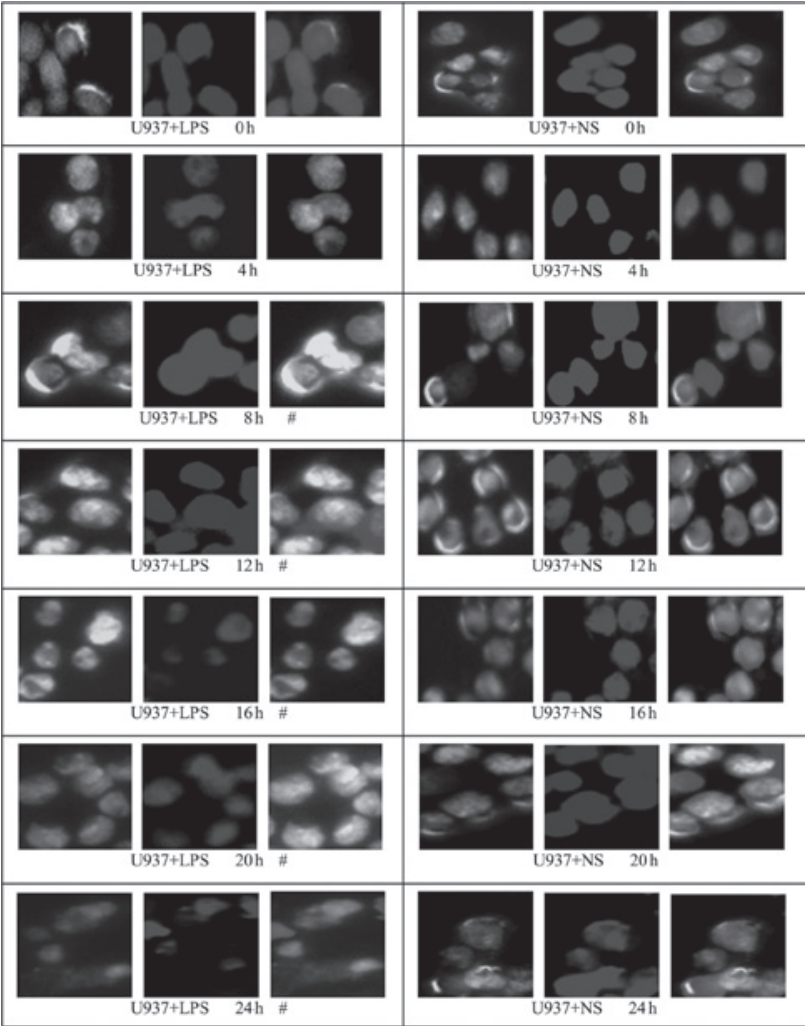

Figure 8. High mobility group box-1 (HMGB1) translocation in U937 cells, as detected by an immunofluorescence assay at different time-points following the addition of lipopolysaccharide (LPS; $400 \mathrm{ng} / \mathrm{ml}$; magnification, $\mathrm{x} 400$ ). At $4 \mathrm{~h}$, green fluorescence was observed in the cytosol of LPS-treated U937 cells and at 8-24 h, substantial fluorescence was detected in the cytosol of LPStreated U937 cells; however, in the corresponding control group, fluorescence was mainly detected in the nuclei. Semi-quantitative analysis revealed that these differences were significant $\left({ }^{*} \mathrm{P}<0.05\right)$.

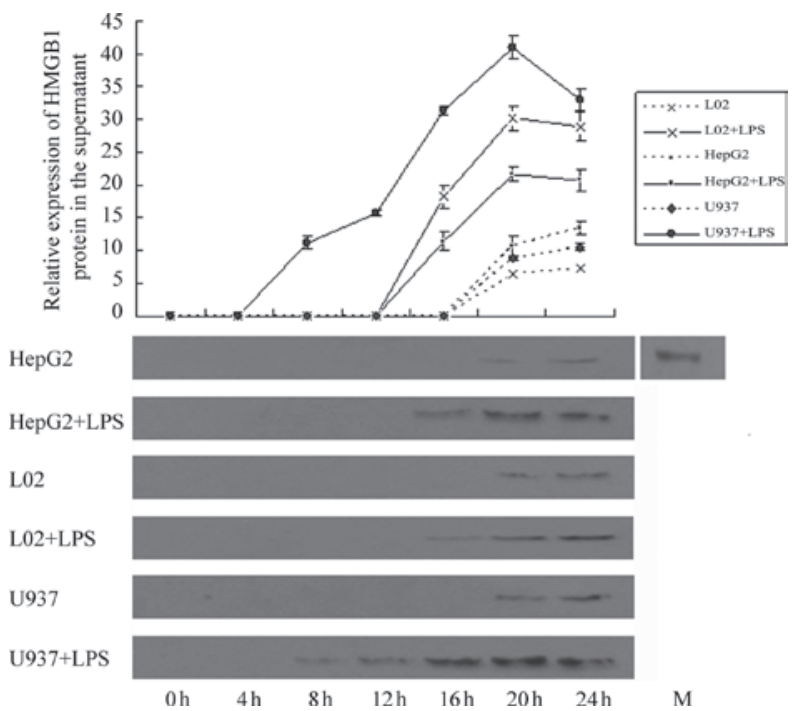

Figure 9. Effect of lipopolysaccharide (LPS) stimuli on high mobility group box-1 (HMGB1) secretion by HepG2, L02 and U937 cells. At 8-24 h, HMGB1 content in the supernatant of U937 cells was significantly higher than that in the corresponding control $(\mathrm{P}<0.05)$. At 16-24 h, HMGB1 content in the supernatants of HepG2 and L02 cells was significantly higher than that in the corresponding controls $(\mathrm{P}<0.05)$. At 20 and $24 \mathrm{~h}$, an extremely small amount of HMGB1 was detected in the three control groups (treated with normal saline; NS) and these amounts were significantly lower than those of the corresponding experimental groups $(\mathrm{P}<0.05)$. Comparison of the HMGB1 secretion levels from the three cell types at the same time-points following LPS treatment demonstrated that U937 cells secreted the highest level of HMGB1. M, reference. 


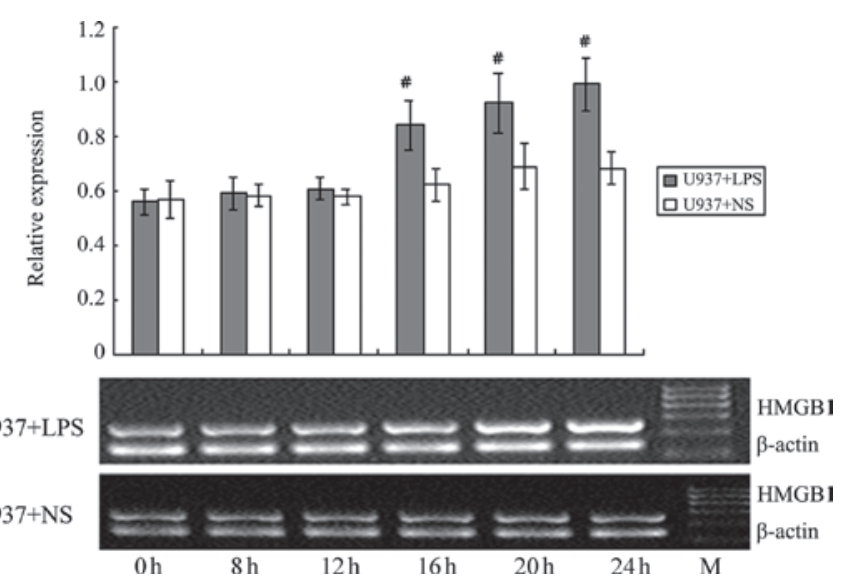

Figure 10. Effect of lipopolysaccharide (LPS) stimuli on high mobility group box-1 (HMGB1) mRNA levels in U937 cells. ${ }^{*}$ Comparison with corresponding control group (NS-treated; $\mathrm{P}<0.05$ ). NS, normal saline; M, reference.

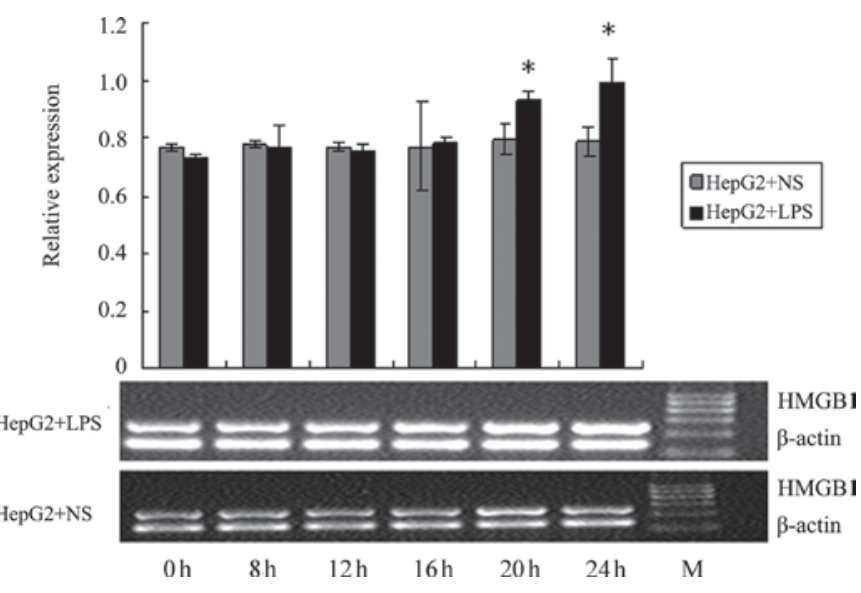

Figure 12. Effect of lipopolysaccharide (LPS) stimuli on high mobility group box-1 (HMGB1) mRNA levels in HepG2 cells. "Comparison with corresponding control group (NS-treated; $\mathrm{P}<0.05$ ). NS, normal saline; $\mathrm{M}$, reference.
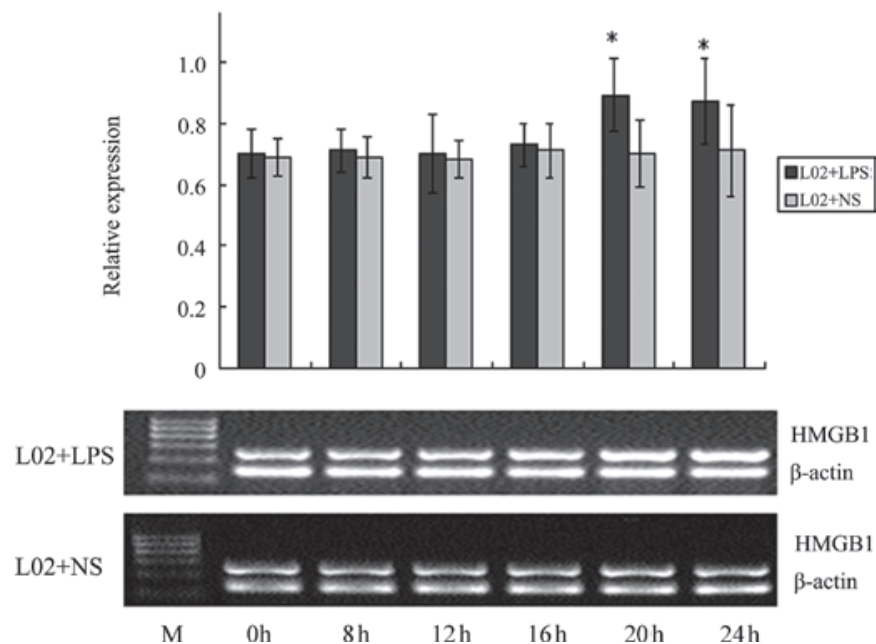

Figure 11. Effect of lipopolysaccharide (LPS) stimuli on high mobility group box-1 (HMGB1) mRNA levels in L02 cells. "Comparison with corresponding control group (NS-treated; $\mathrm{P}<0.05$ ). NS, normal saline; $\mathrm{M}$, reference.

cence, representing specifically labeled HMGB1, was localized within the nucleus and no marked translocation was observed. Since the cytoplasm of U937 cells is relatively small, the cytoplasmic staining of U937 cells was less conspicuous than that of the HepG2 and L02 cells (Fig. 8). Relative fluorescence intensities of the different groups were further analyzed by Image-Pro Plus software and are shown in Table IV; from $8 \mathrm{~h}$, the fluorescence intensity in the cytoplasm of cells from the LPS-treated U937 group was significantly higher than that of the corresponding control group $(\mathrm{P}<0.05)$.

Effect of LPS stimulation on HMGB1 release by Hep G2, LO2 and U937 cells. Western blotting results (Fig. 9) revealed that at $4 \mathrm{~h}$ following the addition of LPS (400 $\mathrm{ng} / \mathrm{ml})$, no HMGB1 band was detected in the supernatants of HepG2, L02 and U937 cells. At 8 h, a weak HMGBl band was observed in the supernatant of U937 cells and at $16 \mathrm{~h}$, a weak HMGBl band was detected in the supernatants of HepG 2 and L02 cells. The photodensities of the HMGB1 bands from the three types of cells gradually increased with time. Semi-quantitative anal- ysis revealed that at $20 \mathrm{~h}, \mathrm{HMGBl}$ content in the cell culture supernatants of the three cell types peaked. At 20 and $24 \mathrm{~h}$, a small quantity of HMGBl was detected in the cell culture supernatant from the control groups (NS-treated), and this quantity differed significantly from the amount of HMGBl in the cell supernatant of the corresponding experimental group for the three types of cells $(\mathrm{P}<0.05)$. Comparison of the quantity of HMGBl secreted by the three cell types following LPS treatment demonstrated that HMGBl secretion by U937 cells was by far the highest, and the differences were significant $(\mathrm{P}<0.05)$. Further comparisons revealed that the amount of HMGB1 secreted by L02 cells at $16 \mathrm{~h}$ was comparable to that by $\mathrm{U} 937$ cells at $13 \mathrm{~h}$, and the amount of HMGB1 secreted by L02 cells at $20 \mathrm{~h}$ was comparable to that by U937 cells at $16 \mathrm{~h}$. With increasing time, the amount of HMGB1 secreted by L02 cells at $24 \mathrm{~h}$ was significantly lower than that by U937 cells at $20 \mathrm{~h}(\mathrm{P}<0.05)$. The amount of HMGB1 secreted by HepG2 cells at $20 \mathrm{~h}$ was comparable to that by U937 cells at $14 \mathrm{~h}$. With an increase in time, the amount of HMGB1 secreted by HepG 2 cells at $24 \mathrm{~h}$ was significantly lower than that by $\mathrm{U} 937$ cells at $20 \mathrm{~h}(\mathrm{P}<0.05)$.

Effect of LPS stimulation on HMGB1 mRNA levels in Hep G2, L02 and U937 cells. RT-PCR was used to detect the HMGB1 mRNA levels in HepG2, L02 and U937 cells at different time-points following the addition of $400 \mathrm{ng} / \mathrm{ml} \mathrm{LPS}$ $(0,4,8,12,20$ and $24 \mathrm{~h})$. NS of the same volume was added to the corresponding control groups. As shown in Figs. 10-12, at 20 and $24 \mathrm{~h}$ following the addition of LPS, HMGB1 mRNA levels in HepG2 and L02 cells were significantly higher than those in the corresponding controls. For U937 cells, the HMGB1 mRNA level at $16 \mathrm{~h}$ was already significantly higher than the corresponding control. The increase in HMGB1 mRNA level induced by LPS in U937 cells occurred earlier than in HepG2 and L02 cells, and the magnitude of the increase was also higher; these differences were all deemed to be significant $(\mathrm{P}<0.05)$.

\section{Discussion}

Under normal conditions, HMGB1 is localized in the nucleus. Thus, the release of HMGB1 from the intracellular to extra- 
cellular space is a prerequisite for its extracellular functions. There are two ways by which HMGB1 may be released; active 'secretion' by activated immune cells and passive 'leaking' from apoptotic cells. Previous studies have demonstrated that non-apoptotic HepG2 cells are capable of releasing HMGB1 $(17,18)$. In this study, we characterized the secretion of late pro-inflammatory cytokine HMGB1 by liver L02 and HepG2 cells.

LPS-induced HMGB1 release in liver cells was not caused by cell damage. $\mathrm{LDH}$ is a damage-related factor; when cultured cells are damaged, a large quantity of LDH may be detected in the culture fluid. Our results revealed that at all time-points, the LDH content in the cell supernatants of every LPS-treated group was not significantly different from that of the corresponding controls, suggesting that at $0-24 \mathrm{~h}$ following the addition of $400 \mathrm{ng} / \mathrm{ml}$ LPS, none of the cells had incurred substantial damage.

Liver cells (L02, HepG2) and U937 cells release HMGB1 when treated with LPS; however, their release characteristics vary. The first difference is reflected in the timing of the release. For U937 cells, at $8 \mathrm{~h}$ following the introduction of LPS, the HMGBl band was detected from the cell culture supernatant, whereas for liver cells (L02, HepG2), a weak HMGB1 band was detected from the supernatant at only $16 \mathrm{~h}$ following stimulation, suggesting that HMGB1 release from the liver cells occurs substantially later than from the immune cell line U937. The second difference is that the amount of HMGB1 released from the control and liver cells differed. Although the amount of HMGB1 detected in the supernatant of LPS-treated U937 cells was relatively small, it remained larger compared with that in the liver cells (L02, HepG2). RT-PCR results revealed that at 20 and $24 \mathrm{~h}$ following the addition of LPS, HMGB1 mRNA levels in the liver cells (L02, HepG2) were significantly higher than those in the corresponding controls. In U937 cells, starting from $16 \mathrm{~h}$, the HMGB1 mRNA levels were already significantly higher than those in the corresponding controls, suggesting that the elevation in HMGB1 mRNA levels occurred earlier in U937 cells vs. liver cells (L02, HepG2). When considering the combined RT-PCR and western blotting results, we noted that for U937 and liver cells (L02, HepG2) at the same effective LPS concentration, the time at which the HMGB1 mRNA level became elevated was later than the time at which the HMGB1 level in the supernatant became elevated, suggesting that increased levels of HMGB1 in the supernatant were not solely from transcription-translation of the increased HMGB1 mRNAs in response to LPS stimulation. The immunofluorescence assay results demonstrated that HMGBl translocation from the nucleus to the cytoplasm was observed at $12 \mathrm{~h}$ in liver cells (L02, HepG2); however, in U937 cells, such translocation occurred at 4-8 h, which was substantially earlier than in the liver cells (L02, HepG2). We speculate that at 0-24 h, the main source of HMGB1 in the supernatant was released from the HMGB1 pool in the nuclei, and was not the result of the regulation of the internal signaling pathway (transcription-translation) in response to stimulation. However, as time progressed, the latter may gradually play a dominant role.

Our study demonstrates that living, non-apoptotic liver cells are capable of secreting and releasing the late inflammatory cytokine HMGB1, and the mechanism of this secretion may be closely associated with the translocation of HMGB1 in the nuclei. Compared with HMGB1 secretion from immune cells, HMGB1 secretion from liver cells occurs later and in a smaller quantity. These results provide an experimental basis for a more complete understanding of the physiological function of the liver. During the development of severe hepatitis, immune cells of the liver, including mononuclear macrophage cells and NK cells, are activated and release inflammatory cytokines, leading to a second attack on the liver that aggravates the damage (20). The results from this study reveal that non-apoptotic liver cells are capable of releasing HMGB1, which further exacerbates the aforementioned inflammatory response cascade. However, HMGB1 release to the extracellular space may also serve as a warning signal to nearby liver cells and affect the taxis of endothelial cells in order to promote the aggregation of endothelial cells and tissue repair. Hence, HMGB1 release by liver cells in response to external stimuli may also be an important step in the self-protection mechanism of the body. This study provides a new approach to investigating the pathogenic mechanism of severe hepatitis. Furthermore, due to the characteristic functions of HMGB1 in the inflammatory network, it may be a new target for the clinical treatment of severe hepatitis.

In conclusion, LPS-stimulated liver cells are capable of secreting the late inflammatory cytokine HMGB1. Compared with HMGB1 release by immune cells, HMGB1 release by liver cells occurs later and in a smaller quantity. Furthermore, this release is associated with HMGB1 translocation and is not dependent on cell death or apoptosis.

\section{Acknowledgements}

This study was supported by grants from the National Natural Science Foundation of China (30972621 and 81101829), the Funding for Doctoral Program of The University of China (20110162110004), the Special Funding for Hunan Innovation of Scientific Research Technics of China (2011TT2060), the Hunan Natural Science Foundation of China (11JJ4074), the Freedom Explore Program of Central South University of China (2011QNZT14) and the Hunan Innovative Experimental Program for Undergraduates of China (BW11479).

\section{References}

1. Yotov WV and St-Arnaud R: Nucleotide sequence of a mouse cDNA encoding the nonhistone chromosomal high mobility group protein-1 (HMG1). Nucleic Acids Res 20: 3516, 1992.

2. Calogero S, Grassi F, Aguzzi A, et al: The lack of chromosomal protein Hmg1 does not disrupt cell growth but causes lethal hypoglycaemia in newborn mice. Nat Genet 22: 276-280, 1999.

3. Landsman D and Bustin M: A signature for the HMG-1 box DNA-binding proteins. Bioessays 15: 539-546, 1993.

4. Landsman D: No HMG-1 box signature. Nature 363: 590, 1993.

5. Melvin VS and Edwards DP: Coregulatory proteins in steroid hormone receptor action: the role of chromatin high mobility group proteins HMG-1 and -2. Steroids 64: 576-586, 1999.

6. Furuita K, Murata S, Jee JG, et al: Structural feature of bent DNA recognized by HMGB1. J Am Chem Soc 133: 5788-5790, 2011.

7. Huttunen HJ and Rauvala H: Amphoterin as an extracellular regulator of cell motility: from discovery to disease. J Intern Med 255: 351-366, 2004.

8. Degryse B, Bonaldi T, Scaffidi P, et al : The high mobility group (HMG) boxes of the nuclear protein HMG1 induce chemotaxis and cytoskeleton reorganization in rat smooth muscle cells. J Cell Biol 152: 1197-1206, 2001.

9. Wang H, Bloom O, Zhang M, et al: HMG-1 as a late mediator of endotoxin lethality in mice. Science 285: 248-251, 1999. 
10. Erlandsson Harris $\mathrm{H}$ and Andersson U: Mini-review: the nuclear protein HMGB1 as a proinflammatory mediator. Eur J Immunol 34: 1503-1512, 2004.

11. Xu H, Yao Y, Su Z, et al: Endogenous HMGB1 contributes to ischemia-reperfusion-induced myocardial apoptosis by potentiating the effect of TNF-alpha/JNK. Am J Physiol Heart Circ Physiol 300: H913-H921, 2011.

12. Luan ZG, Zhang H, Yang PT, et al: HMGB1 activates nuclear factor- $\kappa \mathrm{B}$ signaling by RAGE and increases the production of TNF- $\alpha$ in human umbilical vein endothelial cells. Immunobiology 215: 956-962, 2010.

13. Fiuza C, Bustin M, Talwar S, et al: Inflammation-promoting activity of HMGB1 on human microvascular endothelial cells. Blood 101: 2652-2660, 2003.

14. Park JS, Svetkauskaite D, He Q, et al: Involvement of toll-like receptors 2 and 4 in cellular activation by high mobility group box 1 protein. J Biol Chem 279: 7370-7377, 2004.

15. Gardella S, Andrei C, Ferrera D, et al: The nuclear protein HMGB1 is secreted by monocytes via a non-classical, vesiclemediated secretory pathway. EMBO Rep 3: 995-1001, 2002.
16. Scaffidi P, Misteli T and Bianchi ME: Release of chromatin protein HMGB1 by necrotic cells triggers inflammation. Nature 418: 191-195, 2002.

17. Zhou RG, Fan XG, Liu HB, et al: Study of the extracellular release of HMGB1 in human liver cell line HepG2 cells induced by lipopolysaccharide. Life Science Research 4: 359-364, 2008 (In Chinese).

18. Zhou RG, Fan XG, Liu HB, et al: Study of the extracellular release of HMGB1 in human liver cell line HepG2 cells induced by TNF- $\alpha$. Chin J Immunol 25: 126-131, 2009 (In Chinese).

19. Tsung A, Klune JR, Zhang X, et al: HMGB1 release induced by liver ischemia involves Toll-like receptor 4 dependent reactive oxygen species production and calcium-mediated signaling. J Exp Med 204: 2913-2923, 2007.

20. Jha AK, Nijhawan S and Suchismita A: Sepsis in acute on chronic liver failure. Dig Dis Sci 56: 1245-1246, 2011. 